\title{
DEFINITION OF THE MAIN FEATURES OF THE STUDENT PROJECTS FOR THEIR DEVELOPMENT AND ASSESSMENT IN THE BACHELOR ENGINEERING IN INDUSTRIAL DESIGN AND PRODUCT DEVELOPMENT AT UNIVERSITAT POLITĖCNICA DE VALĖNCIA - CAMPUS OF ALCOI
}

\author{
M. Bonet-Aracil, M. Valor Valor, A. Jordá Vilaplana, S. Sempere Ripoll, E. Juliá \\ Sanchis, L. Pla Ferrando, J.F. Picó Silvestre, J.A. Martínez Cerver \\ Universitat Politècnica de València (SPAIN)
}

\begin{abstract}
The Bachelor Engineering in Industrial Design and Product Development establishes the final project as a compulsory stage to achieve the degree. Due to the wide range of industrial products that can be designed, there is an extensive number of topics. The students can choose their final project according to the specialization they have studied all along the fourth course.
\end{abstract}

At Universitat Politècnica de València - Campus d'Alcoi, three specializations can be studied: a) Product Design; b) Production and Innovation, and c) Textile and Fashion Design.

Due to the multidisciplinary approach, there is a need to define a general index, both for students and lecturers, which contains the minimum contents of every type of project.

A team of lecturers are involved in an education project at Universitat Politècnica de València. At least there is one representative for each specialization. The team has been working based on the last five year presented final projects and with a National Standard UNE 157001:2014 General criteria for the formal preparation of the documents constituting a technical project.

Part of the work consists of analysing the four types of projects and the basic structure for each one, depending on the specialization. In addition, there is a particular project based on communication issues.

The aim of this part of the project is to define the main structure for the minimum contents that these projects must include for their assessment. Finally, a document has been prepared as a basic guideline for students and lecturers, with definitions and instructions. Despite being four different topics, results show a common part which must be fulfilled by every project. Apart from the common part, every specialization has defined the special characteristics to be included.

This document would be useful for every part which plays a role in the process: students to focus on the tasks to develop, a document for lecturers to guide the student and introduce the process and the tribunal to obtain the basis for the evaluation.

Keywords: Design degree, final project, specialization.

\section{INTRODUCTION}

Undoubtedly, nowadays teaching is not only concerned to school and takes place out of the classrooms. Society plays an important role and the education system is moving towards including not only lessons but new technologies. One of the most significant advances in learning process has been the computer. Since the introduction of computer in the learning process the evolution in teaching/learning is varying at vertiginous speed. Some time ago it was thought that computer and the internet would increase the number students working by themselves isolated from the students community. However, the social nets are demonstrating that an interaction can occur although it is not a face to face one it can be useful for learning or to solve some doubts.

Nowadays the lecturer needs a high level of imagination to catch students attention and sometimes implies the use of different techniques. Educators around the world are experimenting with and laying the foundation for new opportunities for learners to access education through connections and technologies that did not exist 10 years ago [1]. There is a wide variety of tools which can reinforce the 
skills a student obtains for example: Concept maps, vee diagrams [2], problem-solving exercises, cooperative student projects, informal group work, simulations, case studies, and role playing [3].

Technological studies usually include the development of a final project which reflects the skills obtained all along the university period, including those obtained by the previously cited tools. Every degree has been designed according to some competences. Some of them are specific to the Industrial Design degree (digital design, etc.) and others are transversal (leadership, effective communication, ...).

The project must be undertaken by the student and a tutor is assigned to support him at any doubt and conducting him throughout the process. The Bachelor Engineering in Industrial Design and Product Development at Universitat Politècnica de València (UPV) - Campus d'Alcoi, offers three specializations: a) Product Design; b) Production and Innovation, and c) Textile and Fashion Design. The students can choose their final project according to the specialization they have studied all along the fourth course.

Along the six years the new structure has been habilitated many complaints from the students have been received regarding the uncertainty the student must face at the initial stage when preparing the final degree project.

Up to some extent, it could be told that you can find as many projects as products can be developed. That is, there is a broad variability of projects. However, in the Project funded by the UPV, authors have worked on the definition of the typology of projects grouping them by common themes and stablishing a guide for the student. The aim of this part of the project was to define the minimum contents a project must include in order to demonstrate the achievement of some learning outcomes.

\section{METHODOLOGY}

The project work is based on an application of knowledge and must face, up to some extent, professional reality [4]. The team was comprised of lecturers who had some expertise on directing that kind of projects. Members have stablished different meetings where each partner presented both the problems when directing a project or when valuating. The methodology could be expressed as the work packages listed below:

- WP 1: Analysis of projects variability.

- WP 2: Definition of compulsory aspects to cover.

- WP 3: Common features and defining a document

- WP 4: Diffusion to the degree community.

\section{RESULTS}

Results would be described according to the above work packages which have been organised in order to structure the tasks to do and stablish a logical division of work.

\subsection{Analysis of projects variability}

Due to Bolonia process for universities adaptation, a new plan of studies was stablished six year ago at Universitat Politècnica de València (Spain). The degree studied at Alcoi campus from UPV is characterized by the specializations which can be studied. They are the ones cited in the introduction section.

Despite having clearly identified the three characteristic areas, the team prepared a list of titles from every project which had been defended by the students in the last 6 years. Later on, the title and the abstract were carefully analysed in order to classify them by topics.

Results show there are four main topics in which the projects can be classified:
a) Product Design
b) Production and Innovation
c) Textile and Fashion Design
d) Communication 
Surprisingly, the vast majority of projects were related not only with the three specialization areas studied at the fourth course but here was a new one related with communication aspects.

\subsection{Definition of compulsory aspects to cover}

Once the four topics for projects have been defined, an expert lecturer was designated as the responsible person to determine which are the main aspects to cover in order to ensure the student can demonstrate the skills acquired and its level and reflects the competences and the level reached.

Every sub-section worked independently. For example, the area of Textile and fashion stablished three meetings according to the contents listed below:

- $1^{\text {st }}$ meeting: The project was exposed to the lecturers in the area and the work programme was defined.

- $2^{\text {nd }}$ meeting: Every lecturer presents the contents which should be included and a brainstorming is created to conclude and define the minimum features a project in this area should include.

- $3^{\text {rd }}$ meeting: Lecturers should have studied the finished projects and define if any of them has not included the basic aspects defined at the $2^{\text {nd }}$ meeting. A discussion is stablished to determine if the aspect/item could be avoided or should be defined as compulsory.

\subsection{Common features and defining a document}

Having finished the second stage, the team exposes the items every area should include. Results from each area have been compared. Every partner discus the relevance of including any of the items which are not common to every area. Finally, the group came up to a final document through a consensus of everyone. This document includes the main features every project belonging to a specific area must include.

The conclusion form the debate was that the compulsory items every student must include in the report structure are:

- Cover: Standard one form UPV Campus d'Alcoi

- Cover: Personalised one.

- Index.

- Introduction.

- Objectives.

- Glossary.

- Aspects to fulfil with the new design.

- Study on every design suggested.

- Technical and aesthetic aspects on the selected design.

- Budget and economical study.

- Conclusions.

Moreover, some annexes can be included and it was observed that every group of projects included graphical information such as drawings, maps, photographs, etc. Thus, this is a common feature which must be included as well.

\subsection{Diffusion to the degree community}

Should the document defined in the previous stage not be spread all along the degree community, the activities conducted previously would lack of sense. Consequently, the document was evaluated by the academic commission, and once it was approved, a mailing was spread both for lecturers and students. 


\section{CONCLUSIONS}

The most striking results to emerge from the data analysed is that a new category was defined related with the final degree project areas. That reveals there is one more specialization than the ones studied at the fourth course.

A final document was created in order to define the main features a final degree project in the bachelor engineering in industrial design and product development at UPV - Campus de Alcoi must include.

This document would be useful for every role present in the process: students to focus on the tasks to develop, a document for lecturers to guide the student and introduce the process and the tribunal to obtain the basis for the evaluation.

\section{ACKNOWLEDGEMENTS}

Authors would like to acknowledge the Agencia Valenciana D’Avaluació I Prospectiva for the financial support to the project referenced PIME/2016/B/026.

\section{REFERENCES}

[1] L. Berge, Zane, and P. Mauri. Collins, eds. Computer mediated communication and the online classroom: distance learning. Cresskill: Hampton press, 1995.

[2] C.J. Bonk, and J. Donald. Cunningham. "Searching for learner-centered, constructivist, and sociocultural components of collaborative educational learning tools." Electronic collaborators: Learner-centered technologies for literacy, apprenticeship, and discourse. Vol 25 pp. 25-50. 1998.

[3] M. Chet, and T. B. Jones. Promoting Active Learning. Strategies for the College Classroom. Jossey-Bass Inc., Publishers, 350 Sansome Street, San Francisco, CA 94104, 1993.

[4] J.E. Mills, and D. F. Treagust. "Engineering education-Is problem-based or project-based learning the answer." Australasian journal of engineering education". vol. 3, no. 2, pp. 2-16. 2003 